Texas A\&M University- San Antonio

Digital Commons@ Texas A\&M University-San Antonio

History Faculty Publications

College of Arts and Sciences

1998

\title{
Basic Incompatibilities Between Evolutionary and Behavioral Archaeology
}

Michael J. O'Brien

Texas AøM University-San Antonio, Mike.Obrien@tamusa.edu

R.L. Lyman

R. D. Leonard

Follow this and additional works at: https://digitalcommons.tamusa.edu/hist_faculty

Part of the Anthropology Commons

\section{Repository Citation}

O'Brien, Michael J.; Lyman, R. L.; and Leonard, R. D., "Basic Incompatibilities Between Evolutionary and Behavioral Archaeology" (1998). History Faculty Publications. 15.

https://digitalcommons.tamusa.edu/hist_faculty/15

This Article is brought to you for free and open access by the College of Arts and Sciences at Digital Commons @ Texas A\&M University- San Antonio. It has been accepted for inclusion in History Faculty Publications by an authorized administrator of Digital Commons @ Texas A\&M University- San Antonio. For more information, please contact deirdre.mcdonald@tamusa.edu. 


\title{
BASIC INCOMPATIBILITIES BETWEEN EVOLUTIONARY AND BEHAVIORAL ARCHAEOLOGY
}

\author{
Michael J. O’Brien, R. Lee Lyman, and Robert D. Leonard
}

\begin{abstract}
Schiffer (1996) recently proposed that, despite some incompatibilities, considerable common ground exists between behavioral archaeology and evolutionary, or selectionist, archaeology. He concludes that there is no fundamental reason why the two approaches cannot work in concert to explain human behavioral change. There are, however, several important reasons why the two programs, at least as currently conceived, cannot work together in any thoroughly integrated fashion. Although both programs employ inference, behavioral archaeology conflates the distinct roles of configurational and immanent properties, searches for nomothetic answers to questions about human behavior, overlooks historical contingency when inferring and explaining the nature of past behavior, and in some cases seems to fall back on vitalism as the mechanism of change. Evolutionary archaeology employs immanent properties inferentially, explicitly acknowledges the importance of the historical contingencies of configurational properties, explains human behavior as being time-and spacebound, and calls upon selection and drift (transmission) as the mechanisins of change. Any attempt to integrate the two approaches must begin by addressing these basic differences.
\end{abstract}

Schiffer (1996) recientemente ha propuesto que, a pesar de algunas incompatibilidades, existen considerables puntos en común entre la arqueología conductual y la arqueología evolucionista, o seleccionista. Concluye que no existen razones fundametales por las que estas dos perspectivas no puedan trabajar en conjunto para explicar los cambios del comportamiento humano. Existen, a pesar de todo, varias razones importantes por lo cual estas dos escuelas, al menos como se les ha concebiclo hasta ahora, no pueden trabajar juntas bajo ningún planteamiento integrado. Aunque las dos escuelas emplean inferencias, la arqueología conductual conjuga el papel distintivo de las propiedades configuracionales e imanentes, busca respuestas nomotéticas a las preguntas sobre el comportamiento humano, pasa por alto las contingencias históricas al inferir y explicar la naturaleza del comportamiento pasado, y en algunas casos parece recaer en el vitalismo como mecanismo del cambio. La arqueología evolucionista emplea inferencialmente las propiedades inmanentes, reconoce explicitamente la importancia de las contingencias históricas en la configuración de las propiedades, explica el comportamiento humano como único en un tiempo y espacio determinado, y considera a la selección y la transmisión como los mecanismos responsables del cambio. Cualquier intento de integrar estas dos escuelas debe comenzar por resolver estas diferencias básicas.

$\mathrm{R}$ ecently, Schiffer (1996) pointed out what he saw as specific areas of concordance between evolutionary archaeology and behavioral archaeology, positing that "there is no fundamental reason why these two programs cannot work in concert to achieve the goal of explaining behavioral (or evolutionary) change in human societies" (Schiffer 1996:643). Schiffer is the prime architect of the behavioral archaeology program (Schiffer 1995a) and, together with colleagues and students at the University of Arizona (e.g., Reid et al. 1974, 1975; Skibo et al. 1995), has produced the majority of articles and books that take a behavioral approach to understanding the archaeological record. He also has been more than accommodating in allowing evolutionists to publish in journals and series that he edits; thus he has had to read not only the manuscripts submitted but also the reviews solicited during the editorial process. As a result, he has more than a passing familiarity with evolutionary archaeology, and hence his observations of possible overlap between it and behavioral archaeology are worth considering in detail.

We agree with some of Schiffer's observations and arguments, but disagree with others. The

Michael J. O'Brien and R. Lee Lyman a Department of Anthropology, University of Missouri, Columbia, MO 65211

Robert D. Leonard a Department of Anthropology, University of New Mexico, Albuquerque, NM 87131

American Antiquity, 63(3), 1998, pp. 485-498.

Copyright $(\mathcal{C}$ by the Society for American Archaeology 
points of disagreement underscore deep differences between the two approaches. Both evolutionary and behavioral archaeology seek to explain humankind's past, and in some cases the data requirements are the same ( $\mathrm{O}$ 'Brien and Holland 1995b), but there are significant differences in epistemology, several of which are well discussed in Schiffer's paper. Hence, we address them only in passing and focus primary attention on metaphysical differences between evolutionism and behavioralism-differences that at present cannot be resolved given the contrasting manner in which behavioralists and evolutionists construct their explanations of the past.

\section{History, Evolutionary Archaeology, and Behavioral Archaeology}

Schiffer focuses the majority of attention on the work of Dunnell, correctly claiming that evolutionary archaeology "had its proximate roots in [Dunnell's] writings . . . especially his 1980 paper in Advances in Archaeological Method and Theory" (Schiffer 1996:646). The 1980 paper to which Schiffer refers (Dunnell 1980) was Dunnell's (1996a:x) "second major foray into evolution and sociobiology," the first having been a conference paper presented in 1978 (Dunnell 1996b). Other papers written late in the 1970 s show the growing influence of Darwinism on Dunnell's thinking (e.g., Dunnell 1978; Dunnell and Wenke 1980). There are two points here. First, Dunnell's thinking was not fully developed in the 1970s - the Advances paper was written, as Dunnell (1996a:x) put it, by a "neophyte." Second, Dunnell has yet to produce a thorough programmatic statement on how to implement his version of evolutionary archaeology. What Dunnell (1996a:xi) takes as his "best" piece of evolutionary archaeology work is an exploration of artifact variation (Dunnell and Feathers 1991) —an extremely critical factor within evolutionary archaeology that has prompted him to remark on more than one occasion (e.g., Dunnell 1989:46) that archaeology must develop units of measurement and description commensurate with theory.

Most of Dunnell's published statements either are directed to particular issues within the larger context of the evolutionary archaeology program (e.g., Dunnell 1995) or are so general that little critical detail is included (e.g., Dunnell 1989, 1992a, 1992b). One must, therefore, to some degree interpret his writings and fill in apparent gaps. We are aided in this task by our collaborations with him (e.g., Dunnell and Leonard 1998; Lyman et al. 1997; O'Brien and Dunnell 1998), yet our collective view does not precisely mirror Dunnell's. Nor should it necessarily do so. But we agree with Dunnell that "one cannot point to a complete and robust theory [of evolutionary archaeology] at this point in time .... [T] still important theoretical issues that require resolution" (Dunnell 1989:42). Biological evolutionary theory cannot simply be lifted wholesale from that realm and applied to sherds, post molds, and arrowheads, just as Darwin's theory could not be lifted from On the Origin of Species and applied wholesale to the fossil record.

These various facts result in Schiffer committing what we view as errors. His description of Dunnell's (1989) discussion of waste behaviorspecifically the Woodland-period mortuary cults of the eastern United States that left behind highly visible burial mounds-as being "almost as behavioral as [a discussion written by] behavioralists" (Schiffer 1996:650) is a case in point. Dunnell (1989:46-49) stated explicitly what the limitations were of what he was doing. Evolutionary archaeology provided only a "gross" understanding of the existence of "waste," and his discussion only served to exemplify the sorts of insights that might result from use of evolutionary theory. The scenario provided was thus of "limited value" and only suggested the "potential" of evolutionary archaeology to help explain the archaeological record; in particular, it indicated which variables were relevant to such scenarios. Schiffer probably would argue that when fleshed out, the scenario would be behavioral, and he would be correct, since human behaviors created the waste. No evolutionary archaeologist ever argued otherwise (O'Brien and Holland 1995b). More importantly, Dunnell (1989) emphasized that (1) if it is granted that artifacts are part of the phenotype, then one must be clear on what makes up an artifact; (2) relevant variables had not yet been described within an evolutionary theory applicable to cultural phenomena such as artifacts; (3) appropriate units for measuring relevant variables in the empirical realm had not been identified and described; and (4) identifying both 
the variables and the units must be commensurate with theory building. Numerous efforts by many individuals have been made in these directions subsequent to publication of Dunnell's article (see references in O'Brien 1996b), but many issues have not been resolved.

\section{What Is Evolutionary Archaeology?}

The premise underlying Darwinian evolutionary archaeology is, as Schiffer (1996:646) points out, that objects occurring in the archaeological record, because they were phenotypic, were shaped by the same evolutionary processes as were the somatic features of their makers and users. This is a shorthand way of saying that the possessors of the objects were acted on by evolutionary processes. Under this perspective, evolution is viewed as the differential persistence of discrete variants (Dunnell 1980:38), regardless of the scale of "variant" being defined. Evolutionary archaeology involves (1) measuring variation-that is, dividing it into discrete sets of empirical units (groups) using ideational units (classes); (2) tracking variants through time and across space to produce a historical narrative about lineages of particular variants; and (3) explaining the differential persistence of individual variants comprising lineages in particular time-space contexts. Selection is a key concept in evolutionary theory, though in modern Darwinian evolutionary theory, selection is only one evolutionary process that works on variation. Few would doubt that selection is the greatest molder of lineages, but it still acts in tandem with other processes such as drift and mutation. Selection is the mechanism that drives much evolutionary change and is external to the system (organisms or cultures) itself. Within Darwinian theory, it serves as a testable explanation of change (Leonard and Reed 1993).

Evolutionary archaeology has many parallels to modern paleobiology (Lyman and O'Brien 1998). It is geared toward providing Darwinian-like explanations of the archaeological record, just as paleobiologists explain the paleontological record. There are two steps: first, build cultural lineages, and second, construct explanations for those lineages being the way they are (O'Hara 1988; Szalay and Bock 1991). Both steps must employ concepts embedded within Darwinian evolutionary theory, such as lineage (a line of development owing its existence to heritability), natural selection (a mechanism of change), a transmission mechanism (which itself is a source of new variants), invention/innovation (another source of new variants), and heritability (denoting continuity, such that similarity is homologous). The last ensures that we are examining change within a lineage rather than merely convergence, in which case similarity is of the analogous sort.

Within paleobiology, some of the best historical studies were written by Simpson (e.g., 1937a, $1937 b, 1937 c)$. Some might question why we refer to such "ancient writings," but what Simpson had to say in the 1930s and 1940s is as relevant today as it was six decades ago (Gould 1980; LaPorte 1983). Some debate has recently arisen as to whether a Simpson-like view is the most appropriate one to adopt in paleobiology (e.g., Gould 1995a, 1995b), and some have, to be sure, adopted (allegedly [see LaPorte 1983]) different views (e.g., Gould and Eldredge 1993), but the important point is that we view these debates as particularly germane to what we see as the central objective of evolutionary archaeology.

We favor definitions of evolution such as "any net directional change or any cumulative change in the characteristics of organisms or populations over many generations - in other words, descent with modification. It explicitly includes the origin as well as the spread of alleles, variants, trait values, or character states. Evolution may occur as a result of natural selection, genetic drift, or both" (Endler 1986:5; see also Richards 1992). Thus, trait variation and inheritance are required for evolutionary change to occur, but fitness differences are not; the last is only required for evolution via natural selection. Such a definition explicitly incorporates both style and function (sensu Dunnell 1978) as kinds of variants of archaeological phenomena. Given this definition, we prefer the methods of evolutionary study used by Gingerich (1991), Simpson (1944, 1975), and Szalay and Bock (1991) to understand the paleontological record (Lyman and O'Brien 1998). We do not deny that what is known as punctuated equilibrium (Eldredge and Gould 1972; Gould and Eldredge 1993) is valuable, nor do we deny its potential applicability to archaeology (e.g., Rosenberg 1994). In part, our preference for earlier methods rather than, say, those favored under 
punctuated equilibrium, resides in the much greater temporal resolution of the archaeological record. This is not to imply that the archaeological record is somehow qualitatively or quantitatively more complete than the paleontological record; the problems with both records are remarkably similar (see overview in Gould 1995a). But both records provide something to which their respective collaborators dealing with living organismswhether people or fruit flies-do not have access. And that is, simply, time.

As Gould (1995a:4) observed, "the short time scale of Drosophila experiments, pigeon breeding, and improvement of crop plants [may provide] direct evidence for the efficacy of selective processes," but these processes may or may not be applicable to "time's vastness." Gould is in part arguing that Darwinian theory must be modified (his and Eldredge's punctuated equilibrium added) to account for the whole of the paleontological record. The important part of Gould's message is that we need not bother studying the fossil record-either paleontological or archaeological-if we can see all evolutionary processes in a petrie dish or among a group of college students. Evolution is historical-it takes place over timeand contingency bound (Beatty 1995), meaning that it is conditioned by what happened at earlier points. Thus, the central objective of paleobiologists and archaeologists is to determine and explain the history - the evolutionary lineages - of the phenomena they study. We believe most behavioral archaeologists would agree with this.

\section{What Is Behavioral Archaeology?}

Schiffer and other practitioners of behavioral archaeology claim to provide a richer and more complete picture of the past than evolutionary archaeologists do: "[B]ehavioral theory, immature though it remains, facilitates the fashioning of historical narratives that are both richly contextualized and audience friendly. More significantly, a behavioral narrative is centered on the actual activities of past people" (Schiffer 1995b:34). Certainly behavioral archaeology provides a picture that is more anthropologically friendly, given its focus on human activities, than evolutionary archaeology does. But to argue that "the focus of theory building in archaeology is ... on what people actually do (and did) in specific activities" (Schiffer 1995b:35) seems to us little more than a holdover from Phillips's (1955:246-247) statement that "New World archaeology is anthropology or it is nothing." Why archaeology should be anything other than archaeology is never specified-other than noting that artifacts are the products of humans-by Phillips, Schiffer, or anyone else who aligns with this position.

Schiffer (1995b:24) states that the "behavioralist demands that historical narratives rest ... on a foundation of well-confirmed behavioral principles." But he also states that constructing behavioral principles or laws "was never viewed by behavioralists as archaeology's final goal. Rather, behavioral inferences provide the basis for generating a view of the past compatible with a particular theoretical stance: the behavioralist premise that the basis of human societies is their complete reliance on complex and intimate relationships between people and artifacts. The study of such relationships, in all times and places, can, behavioralists maintain, lead to the creation of distinctive social theory in archaeology" (Schiffer 1995b:34). We have no dissatisfaction with the "behavioralist premise," but there are two reasons we cannot agree that constructing "behavioral theory to explain variation and change in human behavior, conceived as people-artifact interactions, is archaeology's highest scientific calling" (Schiffer 1995b:35). First, behavioral theory appears to be merely a set of empirical generalizations; second, artifacts, not human behavior, make up the archaeological record.

Behavioral theory is supposed to do two things: (1) improve "behavioral inference" so that it is "sound," thereby making the writing of narratives of behavioral history "rigorous," and (2) answer "with credible theories and laws, the general questions raised in specific [historical] narratives" (Schiffer 1995b:34). The first is accomplished by generating "lawlike statements that, along with other kinds of information, link observations on the archaeological record to behaviors of the past (e.g., Schiffer 1972, 1976)," and by developing a "nomothetic understanding of material culture dynamics" (Schiffer 1995b:22). Such nomothetic principles are "required for reconstructing a behavioral past" (Schiffer 1995b:23) and apparently constitute the basis for building behavioral theory. Historical narratives are "plausible" 
because they entail "theorylike or lawlike generalizations" in the structure of an often-implicit "nomothetic apparatus" (Schiffer 1995b:28).

An example of an underlying premise of a behavioral theory is that "an artifact's performance characteristics cannot all achieve high values in every use activity" (Schiffer 1995b:29). A Swiss army knife can be used to do lots of things, none of them "in the most effective manner," and thus this artifact represents "compromises in activity performance" (Schiffer 1995b:30). The favored behavioral variable in this case is the transportability of a tool, which is "expectable when there is high user mobility and limited transport capability" (Schiffer 1995b:30). High mobility and limited transport capability are certainly behavioral, but do generalized tools always denote such behaviors? Behavioral theory doesn't tell us, because the mobility-transport capability equation is an empirical generalization founded in common sense and denying any contingencies of particular behavioral contexts. Darwinian evolution provides a theoretical understanding of such a tool by noting that design constraints typically result in things-artifacts or organisms - not attaining all-around optimality (e.g., Gans 1988, 1993; Gould 1989); that is, compromises are always being made. Whether high mobility, limited transport, or some other factor results in the production of such a thing is historically contingent-what we term a historical configuration (see below). Why was such a tool built in a particular time-space position? Evolutionary archaeology seeks an answer in two arenas: selective context and evolutionary history.

Behavioral archaeology comprises the reconstruction of behaviors, arranging them in a historical sequence and then explaining that sequence in behavioral terms. Whether or not the sequence also comprises a lineage in a Darwinian sense is not addressed by behavioral archaeology. Why? Because the critical distinction between homologous and analogous similarities is not mentioned in behavioral archaeology theory; thus, a historical narrative may result, but it need not be an evolutionary narrative. That is, a temporal sequence may be produced under the behavioral archaeology program, but there is no apparent attempt to ensure that it is also an evolutionary lineage or a heritability-dependent sequence (Lyman and O'Brien 1997). Further, given the empirical generalization- driven approach of behavioral archaeology in conjunction with the general absence of a concept of style, evolutionary archaeology suggests that behavioral archaeology explanations of Swiss army knives will be strictly functional (e.g., Gould 1997; O'Brien and Holland 1992).

Evolutionary archaeologists also wonder how the reconstructions of behavioral archaeology are tested, since they are inductions or inferences. Dunnell (1989:43-44), for example, notes that by allowing such reconstructions, "[r]elations between behavior and material must be invariant if they are to serve as timeless, spaceless rules for reconstruction" (see O'Brien and Holland 1995b). In other words, a particular structure of particular archaeological stuff in a particular context always and everywhere denotes a particular behavior. In short, equifinality is not a problem for behavioral archaeology because, given sufficient actualistic research, a modern analog for every human behavior that has ever occurred in the past can be found.

\section{Common Ground}

There are three areas of agreement between behavioral archaeology and evolutionary archaeology. First, both programs recognize the importance of human behavior in the context of archaeology. Behavioral archaeologists and few if any evolutionists would disagree with Mayr's (1973:388) assertion that behavior "is perhaps the strongest selection pressure operating in the animal kingdom." Second, as Schiffer points out, identifying and tracking variation evident in the archaeological record is basic to evolutionary archaeology. But the isolation and measurement of variation is not the purview solely of evolutionists. As one of us has stated repeatedly (e.g., O'Brien and Holland 1995a, 1995b), when Schiffer and his colleagues and students break clay test tiles or carry out myriad other experiments in the Laboratory for Traditional Technology at the University of Arizona (e.g., Schiffer 1990; Schiffer and Skibo 1987; Schiffer et al. 1994; Skibo et al. 1989; Vaz Pinto et al. 1987), they are carrying out the same experiments that evolutionary archaeology requires (e.g., Brandon 1994) in order to understand variation in performance characteristics of objects found in the archaeological record. As O'Brien and Holland (1995b:144) point out, technological and functional analyses of how objects 
were made and used are important in evolutionary archaeology. Explanations of past behavior "are derived directly from experimental evidence viewed against the archaeological context containing the materials being examined. We contend that this kind of research agenda - one based on experimental evidence [leading to what we here term mechanical inference]-will allow us to begin to understand not only the evolutionary trajectories of the humans responsible for the technological products but also the nature of selective regimes" (O'Brien and Holland 1995b:144).

The third point of agreement concerns how things in the archaeological record are viewed. Basic to evolutionary archaeology is the view that artifacts represent "the hard parts of the behavioral segment of [past] phenotypes" (Dunnell 1989:44; see Leonard and Jones 1987). When artifacts were made and used, they were as much a part of human phenotypes as nests and log dams are parts of bird and beaver phenotypes, respectively (O'Brien and Holland 1995b). Extending the phenotype (Dawkins 1990) to include nonsomatic features is, as Schiffer points out, something that appeals to behavioral archaeology because it emphasizes the behaviors that result in creation of the objects. Yet Schiffer does not follow through on the evolutionary implications of this notion. He argues that "evolutionary theory itself cannot be rewritten in archaeological context terms: sherds were not part of anyone's phenotype (unless reused), yet a cooking pot-a systemic-context entity operationalized through behavioral inference-was" (Schiffer 1996:649). Later, he (Schiffer 1996:653-654) devotes a page and a half to discussing "Appropriate Units and Scales of Selection." The statement on sherds and the later discussion of units and scales are incompatible with each other from our perspective.

If we paraphrase one of Dunnell's (1980:88) statements that Schiffer (1996:649) isolates, paleobiologists have made significant strides in rewriting evolutionary theory "in terms of variables that are empirical in the [fossil] record." Recall that Darwin made minimal reference to the fossil record (see papers in Nitecki and Nitecki 1992). Paleobiologists have had to develop a suite of terms-some borrowed from functional biology such as homolog, synapomorph, autapomorph, and the like-to denote the variables requisite to applying Darwin's theory to the fossil record. Each variable has a particular significance for determining evolutionary - that is, phylogenetic-history, and each has particular, theoretically founded, empirical manifestations and distributions within the fossil record. Archaeology has only Willey's (1953:363) axiom that "typological similarity [indicates] cultural relatedness." In several respects, this puts the cart before the horse, for as Simpson (1961:69) pointed out when a similar axiom was in use in paleobiology, "individuals do not belong in the same taxon because they are similar, but they are similar because they belong to the same taxon." The significance of this statement is difficult to overemphasize.

Following Schiffer's reasoning, sherds are not part of the phenotype, because a sherd has behavioral relevance only when it is in the systemic context; otherwise it is trash. By the same reasoning, paleobiologists would be surprised to learn that a fossilized fragment of a humerus or a single tooth is not part of an organism's phenotype because the organism is dead. Sherds have attributes - tempering agent, wall thickness, and so forth-any of which, at one time or another, could have been functional. Conversely, any or all could, at one time or another, have been functionally neutral (O'Brien et al. 1994). These attributes are part of a human's phenotype, just as the color of a mammal's hair as represented by a single hair follicle is part of that organism's phenotype, whether or not the hair is attached to the living organism. Schiffer's purely behavioral focus has turned attention away from some of his own most astute observations-namely, those regarding the importance of the scales of units on which evolutionary processes work. There are other differences between evolutionary and behavioral archaeology, and we turn now to some of the most important ones.

\section{Fundamental Differences}

Those who have more than a passing familiarity with the literature on evolutionary archaeology will recognize much of the following. However, given that what we discuss seems to be the major stumbling block to understanding this archaeology and how it differs from other approaches, and that critics of evolutionary archaeology (e.g., Boone and Smith 1998; Spencer 1997) fail to grasp the 
significance of these differences, we believe a few points bear repeating. Rather than parrot what has been said before, we use somewhat different terms for critical concepts in order to make the significance of the message apparent.

Darwinian evolutionary theory deals with history - the explanation of why certain organisms do better than others in a particular environment (Mayr 1961). As a historical science, biological evolution differs ontologically and metaphysically from the ahistorical physical sciences (e.g., Lewontin 1974; Mayr 1987), though the latter offer explanations of how organisms function. If archaeology is taken to be a historical science, the same must hold true for it. The single most fundamental difference between the historical and ahistorical sciences resides in the studied phenomena themselves. As Ereshefsky (1992:91) points out,

The units of evolutionary theory, taxa, are genealogical sequences of organisms which pass on historically acquired information. The units of chemistry and physics, on the other hand, do not consist of such sequences of objects. This difference affords evolutionary theory with a distinctive form of explanation .... In evolutionary biology, many (most?) of the similarities among the members of a taxon can be explained by those similarities being homologies. No such explanation is available for the similarities found among the units of physics and chemistry.... [Chemical and other similarities between] chunks of gold [do] not depend on the transmission of information from one chunk of gold to another [emphasis added].

Simply put, Darwinian evolution, because it concerns heritability and continuity, comprises a materialist ontology, which means that it views relations between and among phenomena as timeand spacebound (Dunnell 1982; O'Brien 1996a). As such, it contrasts sharply with the essentialist ontology of the physical sciences. In essentialism, the "essential properties" of an object dictate whether it is placed in one pile or another; variation between and among objects is viewed as nothing more than "annoying distraction" (Lewontin 1974:5). Importantly, it is not its focus on human behavior that makes behavioral archaeology essentialistic; rather, it is the belief that human behavior can be explained by inventing nomothetic-like principles. Recalling the "behavioralist premise," such principles allow not only the reconstruction of past behaviors but also the construction of social-behavioral theory (Schiffer 1995b:34). But where is the explanatory theory?

\section{Problems with Terms and Concepts}

Schiffer (1996:648) states that because parts of evolutionary archaeology are variously without foundation, contra modern evolutionary biology, these parts undermine efforts to establish a workable theory. Much of Schiffer's criticism has roots in terminology that has plagued archaeology since the early 1960s. Archaeologists regularly confound the concepts of theory, hypothesis, model, and explanation with each other and with other concepts (Leonard and Reed 1996), and they occasionally provide differing definitions that range from redundant to unique. Evolutionary biologists routinely grapple with such issues (see the journal Biology and Philosophy), but archaeologists exacerbate the problem because they often do not define critical terms, assuming we all subconsciously share the same definitional perspective regarding these complex concepts. Schiffer's use of laws, lawlike statements, principles, and generalizations as synonyms, and ideas and theory as synonyms, illustrates this problem.

Schiffer finds it odd that evolutionary archaeology views laws and theories as true by definitionthat is, true in terms of specifying logical relationships, not in some cosmological sense. We believe that this is odd only if one confounds the ideational realm with the phenomenological realm. Such is common in archaeology, where theory and hypothesis are often used synonymously. The most fundamental concepts underlying Darwinian evolutionary archaeology - variation, inheritance, natural selection, inclusive phenotype, replicative success, style, function, and so on-are definitionally true and relate to each other in such a way that evolutionary propositions about the past can be constructed. It is these evolutionary propositionstheoretical claims - about the real world that are testable. We call these hypotheses, which are derived from theory - a situation wholly consistent with practice in modern evolutionary biology, contra Schiffer's claims. With this recognition, Schiffer would no longer find it surprising that "theories have a substantial empirical content" (Schiffer 1996:649). 
The Case of Analogy: Immanent and Configurational Properties

Earlier we indicated that the reconstruction of cultural behavior, one basis of behavioral archaeology, is founded on what we view as the inappropriate use of analogy. We emphasize that we are not saying that analogy is an unacceptable form of reasoning. But the considerable space in archaeological literature devoted to discussing the structure of analogical reasoning and identifying its strengths and weaknesses (e.g., Simms 1992; Stahl 1993) suggests that a good many archaeologists do not have a firm comprehension of such reasoning. Perhaps this should be expected, given that geologists (e.g., Shea 1982) and paleobiologists (e.g., Gould 1965), too, spend a great deal of effort describing analogical reasoning within the context of discussions of uniformitarianism. Simpson's $(1960,1963,1970)$ discussions are helpful in this respect, largely because he describes, in different terms, the sorts of linkages between analogical reasoning and essentialism, as well as the different sorts of linkages between such reasoning and materialism.

What is the significance of the ontological distinction between immanence and configuration when comparing behavioral and evolutionary archaeology? In Simpson's view, the significance is clear:

The unchanging properties of matter and energy [chemistry, mechanics, physics] and the likewise unchanging processes and principles arising therefrom are immanent in the material universe. They are nonhistorical, even though they occur and act in the course of history. The actual state of the universe or of any part of it at a given time, its configuration, is not immanent and is constantly changing. It is contingent... or configurational .... History may be defined as configurational change through time (Simpson 1963:24-25).

Simpson's "immanent" properties and processes compose, in our terms, essentialism; his "configurational" properties are historically contingent and comprise materialism. The dictum that "the present is the key to the past" holds only with respect to essentialist, or immanent, properties and processes: "What we know (or theorize) about the immanent characteristics of the universe is derived from observation of the present" (Simpson
1970:81). Were it not for this simple fact, retrodiction and prediction would be impossible, for the cosmos would be truly random.

Immanent properties and processes are what allow mechanical inferences to be made. The halflife of ${ }^{14} \mathrm{C}$ is an immanent property that allows us to calculate radiocarbon dates; the validity of the radiocarbon-dating method hinges on the uniformitarianist assumption (analogical reasoning) that the half-life of ${ }^{14} \mathrm{C}$ is the same, regardless of place or time. Similarly, the processes that result in biological evolution-genetic transmission, mutation, drift, differential reproduction and survival, and selection-involve immanent properties and processes. The history of an evolutionary lineage is, however, configurational. Every fossil has "its particular as well as its general configurational properties, its significant balance of difference and resemblance [to other fossils], not only because of immanent properties of its constituents and immanent processes that had acted on it, but also because of its history, the configurational sequence by which these individual things arose" (Simpson 1963:27). Thus, "[h]istorical events, whether in the history of the earth, the history of life, or recorded human history, are determined by immanent characteristics of the universe [the source of laws] acting on and within particular configurations, and never by either the immanent or the configurational alone" (Simpson 1963:29).

It is the task of the evolutionist - whether studying fossils, fruit flies, or sherds - to keep immanent and configurational characteristics separate (Szalay and Bock 1991). Note that we are not saying that evolutionists should ignore immanent properties; in fact, we have argued just the opposite (Lyman and O'Brien 1998; O'Brien and Holland 1990, 1995b; O'Brien et al. 1994). Failure to keep the essentialist ontology and its focus on immanent properties distinct from configurational, or historically contingent, properties plagues other disciplines such as paleoecology (e.g., Lawrence 1971) — a discipline that Schiffer (1996:650) perceives as important to modern evolutionary biology. But paleoecological inference is not straightforward when the distinction between immanence and configuration is not maintained (e.g., Paine 1983; Peterson 1983). Two examples demonstrate that Schiffer (1996:651) merges the two.

First, Schiffer (1996:650-651) cites Thomason's 
(1995) Functional Anatomy in Vertebrate Paleontology as an example of the use of behavioral inference by evolutionary biologists, but if anything, "functional anatomy" is founded on immanent properties. We assume Schiffer realizes this, but his focus on function leads us to suspect that he tends to conflate immanent and configurational properties. Second, Schiffer identifies the McKellar principle - which specifies that in frequently maintained activity areas, only small artifacts remain behind as primary refuse (McKellar 1983) —as a nomothetic principle of human behavior. Simpson provides an excellent argument against such a principle being a behavioral law:

A certain person's repeatedly picking up and dropping a certain stone may seem to be a recurrent event in all essentials, but there really is no applicable historical law. Abstraction of a law from such repeated events leads to a nonhistorical law of immanent relationships, perhaps in this case gravity and acceleration or perhaps of neurophysiology, and not to a historical law of which this particular person, picking up a certain stone, at a stated moment, and dropping it a definite number of times would be a determinate instance [Simpson 1963:29-30].

The message here is clear: the present is the key to the past only when immanent properties are involved. Despite the simplicity of what Simpson said, some investigators and commentators (e.g., Watson 1966) have failed to grasp its significance. Precisely the same misunderstanding exists within biological taxonomy (e.g., Mayr 1987, 1996), despite its having been discussed in that context for nearly four decades (e.g., Hull 1965; LaPorte 1997; Mayr 1959; Sober 1980).

\section{Analogy as Behavioral Inference}

Schiffer's (1996:656-657) discussion of "stimulated variation" and the notion that "invention is hardly a random process," while intriguing, is particularly conducive to illustrating some of the differences between nomothetic behavioral principles and Darwinian evolution. In short, "stimulated variation" is simply another way of saying that necessity is the mother of invention. Evolutionary archaeology agrees that certain selective environments likely do stimulate more invention than others, and invention is certainly not random except with respect to the operation of selection. But to invoke humankind's unique problem-solving abil- ities as the cause of culture change is, however, to limit one's analysis substantially. As Steward (1956:72) noted more than 30 years ago: "[A] specific invention is not explained by saying that man is creative." Invoking invention, specifically as it relates to intent, is to view White's (1943:339) "urges, inherent in all living species, to live, to make life more secure, more rich, more full, to insure the perpetuation of the species" as the catalyst for change. Human intent is internal to the cultural system and results in a vitalistic evolutionism that is not testable because the conclusion regarding the mechanism of change is part of the theory.

Appeal to intent as ultimate cause echoes the late nineteenth-century view of Darwinian evolution. Between 1860 and 1900, one of the basic arguments against natural selection, expressed even by some of Darwin's strongest supportersfor example, American botanist Asa Gray-was that it said nothing about the ultimate source of variation. Spencer, for example, believed the problem with natural selection was that "it allowed the individual no freedom to improve itself by its own efforts" (Bowler 1990:171). During the early days of processual archaeology, the role of intent was seriously considered by some processualists. Flannery (1967:122), for example, observed that "individuals do make decisions, but evidence of these individual decisions cannot be recovered by archaeologists."

We do not know how to design a valid empirical test of stimulated variation in the prehistoric past. This, plus the form of evolution that results from invoking such mechanisms as catalysts of change, has prompted us and other evolutionary archaeologists to focus our efforts on areas other than the "variety-generating processes" that behavioral archaeology finds intriguing. Evolutionists have tended to concentrate on what happens to variation after it is generated, instead of looking for laws to explain why it was generated in the first place. It should by now be clear that such laws do not exist. There is, of course, a plethora of mechanisms we might call upon-diffusion, acculturation, invention, and the like-but these are immanent properties of how cultures work. Precisely how and why each of these mechanisms works in particular time-space-cultural contexts is, of course, configurational, or, as some (e.g., Beatty 1995) prefer to label it, historically contingent. 
Ignoring for the moment style, or selectively neutral features, selection is the final arbiter of what is transmitted and perpetuated. It is opportunistic and tinkers with the variation available to produce something that works (Jacobs 1977), regardless of the source of variation (O'Brien and Holland 1995b). This point has been missed by other critics of evolutionary archaeology (Boone and Smith 1998; Spencer 1997). If a workable solution cannot be produced by such tinkering, the organism has little option but to buy a tombstone. If Schiffer is looking for first principles, the closest we can get is the principle of contingency-that what happens at point $\mathrm{C}$ is conditioned to some extent by what happened at point $\mathrm{B}$, which itself is conditioned by what happened at point A. This gives evolutionary lineages their stochastic appearance.

\section{Transmission}

Citing Dunnell (1978), Schiffer (1996:648) states that compared to genetic transmission of variation, "cultural transmission involves different processes and mechanisms, and their understanding may require new laws and theories." He then notes that this statement is self-evident to behavioralists, though "selectionists have been slow to follow up its implications with appropriate nomothetic research" (Schiffer 1996:648). This is true, but not for the reasons Schiffer implies. No one would argue that the study of cultural transmission is unimportant. Researchers such as Boyd and Richerson (1985) and Cavalli-Sforza and Feldman (1981) have made significant strides in understanding the "processes and mechanisms" of cultural transmission. As yet, nothing they have proposed casts doubt on the application of Darwinian evolutionary theory to the archaeological record, though it has been observed that the strides made tend not to explain why transmission occurs the way that it does (Lyman and O'Brien 1998; Sober 1992). The greatest weakness of evolutionary archaeology to date is determining how to measure transmission. Evolutionary biologists know a great deal about the processes and mechanisms of genetic transmission and the appropriate units-genes. Anthropologists are struggling with similar units variously termed "memes," "culturgens," and the like, but how these are to be detected archaeologically is only now being made clear. Applications of transmission models by evo- lutionary archaeologists suggest this may, for a time, be an empirical matter (e.g., Lipo et al. 1997; Neiman 1995).

We agree with Schiffer (1996:648) that it is important to distinguish between the processes that give rise to variation and those that result in the differential persistence of certain variants as opposed to others. In cultural systems, variation results in part from differences in human perception and intention. In fact, Rindos (1985, 1986) argued that if there is a genetic capacity for culture, it actually is a capacity for intentional behavior. Cultural systems, similar to organisms, tend to be overbuilt. That is, they tend to be plastic, adaptive systems capable of accomplishing much more than they regularly do (Boone and Smith 1998). Lability was, no doubt, built by selection (Gould 1991). Efforts to ascribe a function to every attribute of the archaeological record fail to recognize, for example, that the human organism uses only a fraction of its brain power, just as a computer can do much more than we ask of it. Such spandrels-metaphorically, architectural features resulting from design requirements but with no immediate function (Gould and Lewontin 1979; see also Gans 1988) — serve as a stockpile of variation - in some respects stylistic, or adaptively neutral, because they were not shaped by selection but rather by design requirements - that may, in a fluctuating selective environment, be co-opted for some future function (Gould and Vrba 1982). Herein may reside much of what evolutionary archaeology terms style (Dunnell 1978).

Gould (1991) argues that system lability, with particular reference to our overbuilt brains, is crucial to an evolutionary psychology. Fully in concert with a Darwinian viewpoint (Gans 1988; Mayr 1991), we can propose that self-awareness is a spandrel, an unintended outcome of selection having produced a somatic central-processing unit that, in the last 30 years, has built similar units from plastic, metal, and glass. Add reading, writing, language, and other uniquely human or cultural attributes to the list of human-associated traits, many of which may have begun as spandrels. If the last is true, then "[s]tructural consequences have outstripped original bases" (Gould 1991:59). We suspect that those archaeologists with leanings toward the various postprocessual programs could help us gain significant insights here. 


\section{Concluding Remarks}

Behavioral archaeology originally sought to replace culture history and cultural reconstruction and to improve on processual archaeology. It is underlain by an essentialist ontology, which holds that human behavior, regardless of time or space, has configurational properties that all members of the species possess. In such a view, the configurational present is the key to the configurational past. The evolutionary program is underlain by a materialist ontology, which holds that things are always in the process of becoming something else. In such a historical view, the configurational present is not and cannot be the key to the configurational past. Temporal and spatial context matter a great deal. Only immanent properties can be keys to the historical particulars of the past (Lyman and O'Brien 1998). Scientists are free to pose whatever kinds of questions they wish, though logic dictates that the kinds of questions they ask be derived naturally from the kind of science being practiced. When that science is Darwinian evolution, the questions must be of the historical (configurational, contingent, materialist) kind. The last is not to say that essentialism and immanent properties do not have a role to play, because they certainly do. And, at the risk of sounding redundant, it is behavioralists such as Schiffer (e.g., Schiffer and Skibo 1987; Schiffer et al. 1994; Skibo et al. 1989; Vaz Pinto et al. 1987) who have made many of the important strides in understanding the nature of immanent properties.

We agree with Dunnell (1989) that one grand theory generates all of a field's hypotheses and links all explanations. Given our interest in studying the evolutionary history of cultures, the most workable theory is Darwinian evolutionism. Schiffer (1996) states, perhaps facetiously, that "[a]pparently, then, evolutionary theory alone can solve archaeology's myriad explanatory problems." To this we answer, No, it cannot. It can, however, solve archaeology's evolutionary problems. To this end, evolutionary archaeology has constructed concepts and principles to make the theory applicable to the archaeological record. Most fundamentally, artifacts, as well as behaviors that created them, are conceived of as being part of the human phenotype. The concepts of replicative success, style, and function are also necessary inclusions. In our view, modern Darwinian evolutionary theory dictates appropriate methods.
This is not to say that behavioral archaeology does not have significant things to contribute to an evolutionary theory, because it does-a point we have made in the past (O'Brien and Holland 1995b). Other programs, in particular evolutionary ecology (see papers in Maschner 1996) and postprocessualism, given the latter's interest in the symbolic, also have important contributions to make. However, before a truly integrative approach to the historical study of humans and their artifacts emerges - that is, one that investigates the evolutionary pathways of humans and the groups in which they live-we must make clear what the points of contention are among the various approaches. This of necessity will dictate that all interested parties, ourselves included, make sure that we understand the underlying premises of the various approaches in detail.

Acknowledgments. We thank E. J. O'Brien, L. Goldstein, L. Wandsnider, and G. Forbes for their many suggestions on how to improve the manuscript. Helpful comments were received from T. Van Pool, G. Raymond, G. Rakita, E. Hill, T. Hurt, L. Lundquist, J. O'Connell, and several anonymous reviewers. Finally, we thank M. B. Schiffer for his comments on the final draft. We appreciate his constructive criticism of it, but more importantly we appreciate the forums he has afforded evolutionary archaeologists over the years in the several journals he has edited.

\section{References Cited}

Beatty, J.

1995 The Evolutionary Contingency Thesis. In Concepts, Theories, and Rationality in the Biological Sciences, edited by G. Wolters and J. G. Lennox, pp. 45-81. University of Pittsburgh Press, Pittsburgh.

Boone, J. L., and E. A. Smith

1998 Is It Evolution Yet? A Critique of Evolutionary Archaeology. Current Anthropology 39:S141-S173.

Bowler, P. J.

1990 Charles Darwin: The Man and His Influence. Blackwell, Oxford.

Boyd, R., and P. J. Richerson

1985 Culture and the Evolutionary Process. University of Chicago Press, Chicago.

Brandon, R. N.

1994 Theory and Experiment in Evolutionary Biology. Synthese 99:59-73.

Cavalli-Sforza, L. L., and M. W. Feldman

1981 Cultural Transmission and Evolution: A Quantitative Approach. Princeton University Press, Princeton, New Jersey.

Dawkins, R.

1990 The Extended Phenotype: The Long Reach of the Gene. Oxford University Press, Oxford.

Dunnell, R. C.

1978 Style and Function: A Fundamental Dichotomy. American Antiquity 43:192-202. 
1980 Evolutionary Theory and Archaeology. In Advances in Archaeological Method and Theory, vol. 3, edited by M. B. Schiffer, pp. 35-99. Academic Press, New York.

1982 Science, Social Science, and Common Sense: The Agonizing Dilemma of Modern Archaeology. Journal of Anthropological Research 38:1-25.

1989 Aspects of the Application of Evolutionary Theory in Archaeology. In Archaeological Thought in America, edited by C. C. Lamberg-Karlovsky, pp. 35-49. Cambridge University Press, Cambridge.

1992a Archaeology and Evolutionary Science. In Quandaries and Quests: Visions of Archaeology's Future, edited by L. Wandsnider, pp. 209-224. Occasional Paper No. 20. Center for Archaeological Investigations, Southern Illinois University, Carbondale.

1992b Is a Scientific Archaeology Possible? In Metaarchaeology, edited by L. Embree, pp. 75-97. Boston Studies in the Philosophy of Science, vol. 147. Kluwer, Dortrecht, The Netherlands.

1995 What Is It That Actually Evolves? In Evolutionary Archaeology: Methodological Issues, edited by P. A. Teltser, pp. 33-50. University of Arizona Press, Tucson.

1996a Foreword. In Evolutionary Archaeology: Theory and Application, edited by M. J. O'Brien, pp. vii-xii. University of Utah Press, Salt Lake City.

1996b Natural Selection, Scale, and Cultural Evolution: Some Preliminary Considerations. In Evolutionary Archaeology: Theory and Application, edited by M. J. O'Brien, pp. 24-29. University of Utah Press, Salt Lake City.

Dunnell, R. C., and J. K. Feathers

1991 Later Woodland Manifestations of the Malden Plain, Southeast Missouri. In Stability, Transformation, and Variation: The Late Woodland Southeast, edited by M. S. Nassaney and C. R. Cobb, pp. 21-45. Plenum Press, New York.

Dunnell, R. C., and R. D. Leonard (editors)

1998 Explanation of Change: Case Studies in Evolutionary Archaeology. Manuscript on file, Department of Anthropology, University of New Mexico, Albuquerque.

Dunnell, R. C, and R. J. Wenke

1980 Cultural and Scientific Evolution: Some Comments on The Decline and Rise of Mesopotamian Civilization, by N. Yoffee. American Antiquity 45:605-609.

Eldredge, N., and S. J. Gould

1972 Punctuated Equilibria: An Alternative to Phyletic Gradualism. In Models in Paleobiology, edited by T. J. M. Schopf, pp. 82-115. Freeman, Cooper, San Francisco.

Endler, J. A

1986 Natural Selection in the Wild. Princeton University Press, Princeton, New Jersey.

Ereshefsky, M.

1992 The Historical Nature of Evolutionary Theory. In History and Evolution, edited by M. H. Nitecki and D. V. Nitecki, pp. 81-99. State University of New York Press, Albany.

Flannery, K. V.

1967 Culture History v. Cultural Process: A Debate in American Archaeology. Scientific American 217(2):119-122.

Gans, C.

1988 Adaptation and the Form-Function Relation. American Zoologist 28:681-697.

1993 On the Merits of Adequacy. American Journal of Science 293A:391-406.

Gingerich, P. D.

1991 Fossils and Evolution. In Evolution of Life: Fossils,
Molecules, and Culture, edited by S. Osawa and T. Honjo, pp. 3-20. Springer-Verlag, Tokyo.

Gould, S. J.

1965 Is Uniformitarianism Necessary? American Journal of Science 263:223-228.

1980 Paleontology. In The Evolutionary Synthesis: Perspectives on the Unification of Biology, edited by E. Mayr and W. B. Provine, pp. 153-172. Harvard University Press, Cambridge, Massachusetts.

1989 A Developmental Constraint in Cerion, with Comments on the Definition and Interpretation of Constraint in Evolution. Evolution 43:516-539.

1991 Exaptation: A Crucial Tool for an Evolutionary Psychology. Journal of Social Issues 47(3):43-65.

1995a A Task for Paleobiology at the Threshold of Majority. Paleobiology 21:1-14.

1995b Tempo and Mode in the Macroevolutionary Reconstruction of Darwinism. In Tempo and Mode in Evolution, edited by W. M. Fitch and F. J. Ayala, pp. 125-144. National Academy Press, Washington, D.C.

1997 The Exaptive Excellence of Spandrels as a Term and Prototype. Proceedings of the National Academy of Sciences 94:10750-10755.

Gould, S. J., and N. Eldredge

1993 Punctuated Equilibrium Comes of Age. Nature 366:223-227.

Gould, S. J., and R. C. Lewontin

1979 The Spandrels of San Marco and the Panglossian Paradigm: A Critique of the Adaptationist Programme. Proceedings of the Royal Society of London series B, 205:581-598.

Gould, S. J., and E. S. Vrba

1982 Exaptation-A Missing Term in the Science of Form. Paleobiology 8:4-15.

Hull, D. L.

1965 The Effect of Essentialism on Taxonomy-Two Thousand Years of Stasis. British Journal for the Philosophy of Science 15:314-326; 16:1-18.

Jacobs, F.

1977 Evolution and Tinkering. Science 196:1161-1166.

LaPorte, J.

1997 Essential Membership. Philosophy of Science 64:96-112.

LaPorte, L. F.

1983 Simpson's Tempo and Mode in Evolution Revisited. Proceedings of the American Philosophical Society 127:365-417.

Lawrence, D. R.

1971 The Nature and Structure of Paleoecology. Journal of Paleontology 45:593-607.

Leonard, R. D., and G. T. Jones

1987 Elements of an Inclusive Evolutionary Model for Archaeology. Journal of Anthropological Archaeology 6:199-219.

Leonard, R. D., and H. E. Reed

1993 Population Aggregation in the Prehistoric American Southwest: A Selectionist Model. American Antiquity 58:648-661.

1996 Theory, Models, Explanation, and the Record: Response to Kohler and Sebastian. American Antiquity 61:603-608.

Lewontin, R. C.

1974 The Genetic Basis of Evolutionary Change. Columbia University Press, New York.

Lipo, C., M. Madsen, R. C. Dunnell, and T. Hunt

1997 Population Structure, Cultural Transmission, and Frequency Seriation. Journal of Anthropological Archaeology 16:301-333. 
Lyman, R. L., and M. J. O'Brien

1997 The Concept of Evolution in Early Twentieth-Century Americanist Archaeology. In Rediscovering Darwin: Evolutionary Theory in Archaeological Explanation, edited by C. M. Barton and G. A. Clark, pp. 21-48. Archeological Papers No. 7. American Anthropological Association, Arlington, Virginia.

1998 The Goals of Evolutionary Archaeology: History and Explanation. Current Anthropology 39, in press.

Lyman, R. L., M. J. O'Brien, and R. C. Dunnell

1997 The Rise and Fall of Culture History. Plenum, New York.

McKellar, J. A.

1983 Correlates and the Explanation of Distributions. Atlatl, Occasional Papers No. 4. Anthropology Club, University of Arizona, Tucson.

Maschner, H. D. G. (editor)

1996 Darwinian Archaeologies. Plenum, New York.

Mayr, E.

1959 Darwin and the Evolutionary Theory in Biology. In Evolution and Anthropology: A Centennial Appraisal, edited by B. J. Meggers, pp. 1-10. Anthropological Society of Washington, Washington, D.C.

1961 Cause and Effect in Biology. Science 134:1501-1506.

1973 Populations, Species, and Evolution. Harvard University Press, Cambridge, Massachusetts.

1987 The Ontological Status of Species: Scientific Progress and Philosophical Terminology. Biology and Philosophy 2:145-166.

1991 One Long Argument: Charles Darwin and the Genesis of Modern Evolutionary Thought. Harvard University Press, Cambridge, Massachusetts.

1996 What Is a Species, and What Is Not? Philosophy of Science 63:262-277.

Neiman, F.

1995 Stylistic Variation in Evolutionary Perspective: Inferences from Decorative Diversity and Interassemblage Distance in Illinois Woodland Ceramic Assemblages. American Antiquity 60:7-36.

Nitecki, M. H., and D. V. Nitecki (editors)

1992 History and Evolution. State University of New York Press, New York.

O'Brien, M. J.

1996a The Historical Development of an Evolutionary Archaeology. In Darwinian Archaeologies, edited by $\mathbf{H}$. D. G. Maschner, pp. 17-32. Plenum, New York.

O'Brien, M. J. (editor)

1996b Evolutionary Archaeology: Theory and Application. University of Utah Press, Salt Lake City.

O'Brien, M. J., and R. C. Dunnell (editors)

1998 Changing Perspectives on the Archaeology of the Central Mississippi Valley. University of Alabama Press, Tuscaloosa.

O'Brien, M. J., and T. D. Holland

1990 Variation, Selection, and the Archaeological Record. In Archaeological Method and Theory, vol. 2, edited by M. B. Schiffer, pp. 31-79. University of Arizona Press, Tucson.

1992 The Role of Adaptation in Archaeological Explanation. American Antiquity 57:36-59.

1995a The Nature and Premise of a Selection-based Archaeology. In Evolutionary Archaeology: Methodological Issues, edited by P. A. Teltser, pp. 175-200. University of Arizona Press, Tucson.

1995b Behavioral Archaeology and the Extended Phenotype. In Expanding Archaeology, edited by J. M. Skibo, W. H. Walker, and A. E. Nielsen, pp. 143-161. University of Utah Press, Salt Lake City.
O'Brien, M. J., T. D. Holland, R. J. Hoard, and G. L. Fox 1994 Evolutionary Implications of Design and Performance Characteristics of Prehistoric Pottery. Journal of Archaeological Method and Theory 1:259-304.

O'Hara, R. J.

1988 Homage to Clio, or, Toward an Historical Philosophy for Evolutionary Biology. Systematic Zoology $37: 142-155$

Paine, R. T.

1983 On Paleoecology: An Attempt to Impose Order on Chaos. Paleobiology 9:86-90.

Peterson, C. H.

1983 The Pervasive Biological Explanation. Paleobiology 9:429-436.

Phillips, P.

1955 American Archaeology and General Anthropological Theory. Southwestern Journal of Anthropology' 11:246-250.

Reid, J. J., W. L. Rathje, and M. B. Schiffer

1974 Expanding Archaeology. American Antiquity 39:125-126.

Reid, J. J., M. B. Schiffer, and W. L. Rathje

1975 Behavioral Archaeology: Four Strategies. American Anthropologist 77:864-869.

Richards, R. I.

1992 Evolution. In Keywords in Evolutionary Biology, edited by E. F. Keller and E. A. Lloyd, pp. 95-105. Harvard University Press, Cambridge, Massachusetts.

Rindos, D.

1985 Darwinian Selection, Symbolic Variation, and the Evolution of Culture. Current Anthropology 26:65-88.

1986 The Evolution of the Capacity for Culture: Sociobiology, Structuralism, and Cultural Selection. Current Anthropologv 27:315-332.

Rosenberg, $\mathrm{M}$.

1994 Pattern, Process, and Hierarchy in the Evolution of Culture. Journal of Anthropological Archaeology 13:307-340.

Schiffer, M. B.

1972 Archaeological Context and Systemic Context. American Antiquity 37:156-165.

1976 Behavioral Archeology. Academic Press, New York.

1990 The Influence of Surface Treatment on Heating Effectiveness of Ceramic Vessels. Journal of Archaeological Science 17:373-381.

1995a Behavioral Archaeology: First Principles. University of Utah Press, Salt Lake City.

1995b Social Theory and History in Behavioral Archaeology. In Expanding Archaeology, edited by J. M. Skibo, W. H. Walker, and A. E. Nielsen, pp. 22-35. University of Utah Press, Salt Lake City.

1996 Some Relationships between Behavioral and Evolutionary Archaeologies. American Antiquity 61:643-662.

Schiffer, M. B., and J. M. Skibo

1987 Theory and Experiment in the Study of Technological Change. Current Anthropology 28:595-622.

Schiffer, M. B., J. M. Skibo, T. C. Boelke, M. A. Neupert, and M. Aronson

1994 New Perspectives on Experimental Archaeology: Surface Treatments and Thermal Response of the Clay Cooking Pot. American Antiquity 59:197-217.

Shea, J. H.

1982 Twelve Fallacies of Uniformitarianism. Geology $10: 455-460$.

Simms, S. R.

1992 Ethnoarchaeology: Obnoxious Spectator, Trivial 
Pursuit, or the Keys to a Time Machine? In Quandaries and Quests: Visions of Archaeology's Future, edited by L. Wandsnider, pp. 186-198. Occasional Paper No. 20. Center for Archaeological Investigations, Southern Illinois University, Carbondale.

Simpson, G. G.

1937a Notes on the Clark Fork, Upper Paleocene, Fauna. American Museum Novitates No. 954. American Museum of Natural History, New York.

1937b Patterns of Phyletic Evolution. Geological Society of America Bulletin 48:303-314.

1937c Super-Specific Variation in Nature and in Classification from the View-Point of Paleontology. American Naturalist 71:236-267.

1944 Tempo and Mode in Evolution. Columbia University Press, New York.

1960 The History of Life. In Evolution after Darwin, vol. 1: The Evolution of Life, edited by S. Tax, pp. 117-180. University of Chicago Press, Chicago.

1961 Principles of Animal Taxonomy. Columbia University Press, New York.

1963 Historical Science. In The Fabric of Geology, edited by C. C. Albritton, Jr., pp. 24-48. Freeman, Cooper, Stanford, California.

1970 Uniformitarianism: An Inquiry into Principle, Theory, and Method in Geohistory and Biohistory. In Essays in Evolution and Genetics in Honor of Theodosius Dobzhansky, edited by M. K. Hecht and W. C. Steere, pp. 43-96. Appleton, New York.

1975 Recent Advances in Methods of Phylogenetic Inference. In Phylogeny of Primates: A Multidisciplinary Approach, edited by W. P. Luckett and F. S. Szalay, pp. 3-19. Plenum, New York.

Skibo, J. M., M. B. Schiffer, and K. C. Reid

1989 Organic Tempered Pottery: An Experimental Study. American Antiquity 54:122-146.

Skibo, J. M., W. H. Walker, and A. E. Nielsen (editors)

1995 Expanding Archaeology. University of Utah Press, Salt Lake City.

Sober, E.

1980 Evolution, Population Thinking, and Essentialism. Philosophy of Science 47:350-383.
1992 Models of Cultural Evolution. In Trees of Life, edited by P. Griffiths, pp. 17-39. Kluwer, Dordrecht, The Netherlands.

Spencer, C. S.

1997 Evolutionary Approaches in Archaeology. Journal of Archaeological Research 5:209-264.

Stahl, A. B.

1993 Concepts of Time and Approaches to Archaeological Reasoning in Historical Perspective. American Antiquity 58:235-260.

Steward, J. H.

1956 Cultural Evolution. Scientific American 194(5):69-80.

Szalay, F. S., and W. J. Bock

1991 Evolutionary Theory and Systematics: Relationships between Process and Pattern. Zeitschrift für Zoologische Systematik und Evolutionsforschung 29:1-39.

Thomason, J. J.

1995 Functional Morphology in Vertebrate Paleontology. Cambridge University Press, Cambridge.

Vaz Pinto, I., M. B. Schiffer, S. Smith, and J. M. Skibo

1987 Effects of Temper on Ceramic Abrasion Resistance: A Preliminary Investigation. Archeomaterials 1:119-134.

Watson, R. A.

1966 Discussion: Is Geology Different: A Critical Discussion of "The Fabric of Geology." Philosophy of Science 33:172-185.

White, L. A.

1943 Energy and the Evolution of Culture. American Anthropologist 45:335-356.

Willey, G. R.

1953 Archaeological Theories and Interpretation: New World. In Anthropology Today, edited by A. L. Kroeber, pp. 361-385. University of Chicago Press, Chicago.

Received March 10, 1997; revised February 3, 1998; revised February 12, 1998. 